\title{
Profitability of Digitalization on the Example of Precision Farming
}

\author{
Balanovska T.I., Gogulya O.P., Koshchenko K.V., Troian A.V., Yazlyuk B.O.
}

\begin{abstract}
The process of digitalization has long embraced all spheres of human activity, and it is the turn of such traditional industries as agriculture. At this stage of human development, increasing yields is attractive from the point of view of increasing the profitability of the agricultural business, but not yet from the point of view of the food crisis. For a long time, the competitiveness of farmers depended only on the amount of land, the vagaries of the weather and the experience of agronomists that are not enough in the modern world. Agricultural companies that are actively introducing technological innovations can harvest more in a smaller area than its competitors with a larger field but without innovations. The article reveals the urgent issues of the expediency of digitalization of the agricultural sector, shows the experience of farmers from different countries in the implementation of precision farming technologies and monitoring systems, and also considers the prospects and profitability of introducing agricultural technological innovations.
\end{abstract}

Keywords: agricultural business, digitalization, precision farming, productivity of land.

\section{INTRODUCTION}

Such a model worked for many years: there is an agronomist who solves all problems and tasks basing on his knowledge. But the human brain cannot hold and analyze as much information as a computer can. Especially in matters of statistical analysis, estimation, correlation of different circumstances among itself.

Therefore, digitalization in the agricultural sector is the transfer to the information system of a huge array of data describing all the characteristics of the fields: agrochemical, physical and chemical, climate history, crop history, history of pesticide application, norms, productivity of land, etc. P. This is a huge array of data, for example, within the DigitalAgribusiness system [1] - this is 270 groups (each of which has about 3,5,6 indicators). This is the information that must be used so that the system, for example, correctly calculates the production plan. Proper data handling is the key to the efficiency of the agricultural business in modern conditions of technological growth.

Digitalization is, in fact, a new format for using data to make the right business decisions.

Revised Version Manuscript Received on 15 September, 2019.

Balanovska T.I., National University of Life and Environmental Science, Kyiv, Ukraine. (Email: balanovskaya@nubip.edu.ua)

Gogulya O.P., National University of Life and Environmental Science, Kyiv, Ukraine. (Email: gogulya.o.p@nubip.edu.ua)

Koshchenko K.V., "VideCom" Company, Kyiv, Ukraine. (Email: phoenixbounty@gmail.com)

Troian A.V., National University of Life and Environmental Science, Kyiv, Ukraine. (Email: alina.v.troyan@gmail.com)

Yazlyuk B.O., Ternopil National Economic University, Ternopil, Ukraine.
Processes, data, algorithms are very important components for the modern model of work of agricultural companies. A reliable history of fields, quality guides and algorithms will help the system better than any person to forecast the results and plan actions to achieve effective indicators.

The introduction of such a system requires a large number of new devices, gadgets that help to realize the project. For example, field sensors are able to signal the moisture content in the soil - this is very important as part of the spring sowing campaign. You can see the dynamics of changes in these field indicators online.

On the other hand, if we talk about monitoring, a lot of start-ups and technologies have already appeared that allow analyzing satellite photos or photos from drones in a different way. Due to the knowledge base and machine learning algorithms, the first symptoms of diseases or the appearance of weeds can be recognized from the photos. You can pre-identify the problem, plan and implement preventive measures.

The agricultural business is turning into a business that requires maximum precision, the most accurate, jewelry handling of data. This will help in achieving two key goals: grow more and manage costs efficiently, achieving optimal efficiency from each field.

The maximum productivity of land depends on the specific climatic zone, specific soils. All fields have its own limit, and if this limit is not known, the agricultural producer can spend super expensive hybrids, fertilizers on this field, without ever achieving an increase in productivity.

In the current agrarian economy, when world product prices are not rising, good cost management is a very important aspect. But if all the data is not converted to digital format, downloaded into the appropriate system, then there is no need to talk about a breakthrough, an increase in domestic production and the efficiency of Ukrainian farmers.

\section{RESULTS}

Today, everyone needs digitalization. There are small, medium and large agricultural companies. All of them form a significant part of Ukraine's GDP and all of them are interested in growing more, spending less with a thrifty attitude to the land.

But the processes of the farmer and the agricultural company have its own characteristics, so we are now talking about a digitalization model for medium and large companies: from 10-20 thousand hectares. The larger the 
land bank needs more critical data analysis. A large structure is a large number of employees. The more people cause the higher possibility of errors. Therefore, even perfect planning can be crossed out by a large number of errors in implementation. It is necessary to change processes; it is necessary to change corporate thinking.

For large agricultural holdings, digital transformation is not so much a new high-quality software, but a collective transformation: how people approach their work, how they realize tasks.

Smaller farms need basic services of crops planning and fields monitoring. If an enterprise has 10-15 fields, the agronomist can naturally know them thoroughly, but the brain of agronomist has its own limitations that was already discussed. This is a huge number of enterprises in each area of Ukraine, and its coverage with basic services is now not very significant. The use of modern technology is becoming increasingly relevant throughout the world as the world's population is constantly and rapidly growing and land resources remain the same as demonstrated on Fig. 1.

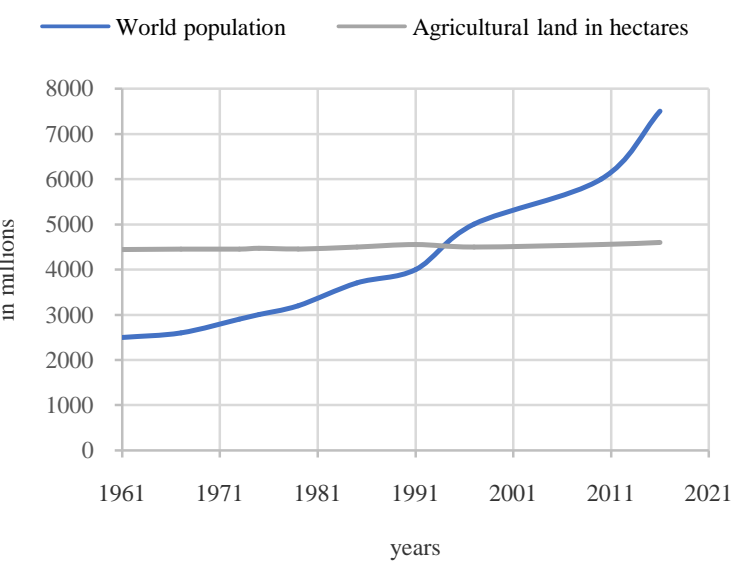

Fig. 1.Quantity of population and agricultural land.

Therefore, the faster the digitalization popularity reaches the smallest farmer with 100-500 hectares of land, the faster this will qualitatively affect Ukraine's performance in the world grain and oilseed production market. Large farms are only 4-6 million hectares. The rest is essentially middle and small farms. And they provide a significant part of agricultural production. Therefore, digitalization in order to maximize the efficient use of land, to obtain the best yield should reach them. And then we will see a qualitative breakthrough in the country as a whole, and not just a separate agricultural holding. Goldman Sachs [2] conducted research and showed in figures how important to introduce technological innovations and increase the productivity of agricultural companies, some indicators can be seen in Table I.
Table- I: Precision farming in numbers

\begin{tabular}{|c|c|}
\hline Numbers & $\begin{array}{c}\text { Reasons to implement technology of } \\
\text { precision farming }\end{array}$ \\
\hline 9,7 bn & $\begin{array}{l}\text { Expected world population by } 2050, \\
\text { translating into } 70 \% \text { required growth in } \\
\text { global food supply from current levels }\end{array}$ \\
\hline $40 \%$ & $\begin{array}{l}\text { Percentage of grain consumption in } 2015 \\
\text { that China - the world's most populous } \\
\text { country - imported }\end{array}$ \\
\hline $70 \%$ & $\begin{array}{l}\text { Potential tech-driven improvement in yields } \\
\text { by } 2050\end{array}$ \\
\hline $50 \%$ & $\begin{array}{l}\text { Potential reduction in water waste with } \\
\text { precision irrigation systems paired with } \\
\text { water sensors }\end{array}$ \\
\hline $40 \%$ & Percentage of over-fertilized fields \\
\hline $15-20 \%$ & $\begin{array}{l}\text { Yield loss suffered from inadequate } \\
15 \%-20 \% \text { fertilizer application }\end{array}$ \\
\hline
\end{tabular}

All companies are at different levels of technological development. But if we talk about the first elementary steps, then first it needs to collect information about the fields. Then these data must be entered on the card of some of the systems. The agricultural producer must understand where his fields are, what is its contour, what is the composition of soils, what is its history. It should also provide at least basic monitoring: these are satellite photos, the NDVI (Normalized Difference Vegetation Index) [3], which shows how well or poorly the crop is developing, what are the problems in the fields.

The next step is the technique used, with what precision farming equipment it is equipped from the factory, how a farmer or agricultural producer can receive data, where he can analyze it. If the farmer does not see the data from the equipment - this is no longer precision farming, this is the previous century. Plus, equipment for precision farming, with which it can be performed precise operations, reduced the number of operations in the field, and increased the final efficiency associated with how the plant develops.

This is a basic level. The agricultural producer must see how the culture grows, what problems there are in a certain area.

Further to this elementary basis, it is necessary to attach more advanced services directly related to precision farming. Formation of task maps for agricultural machinery with preservation of history. How was the sowing carried out this year, were fertilizers added, how to sow in the following: from right to left or from left to right, north-south or west-east. The seeding rate, fertilizers are indicators that have influence on the final result. There are different technologies, and all this is important to remember.

According to the research of Goldman Sachs [2], in the case of precision farming, the yield will increase by $70 \%$, which will increase the target market till 2050 by about $\$ 240$ billion (Fig. 2). 


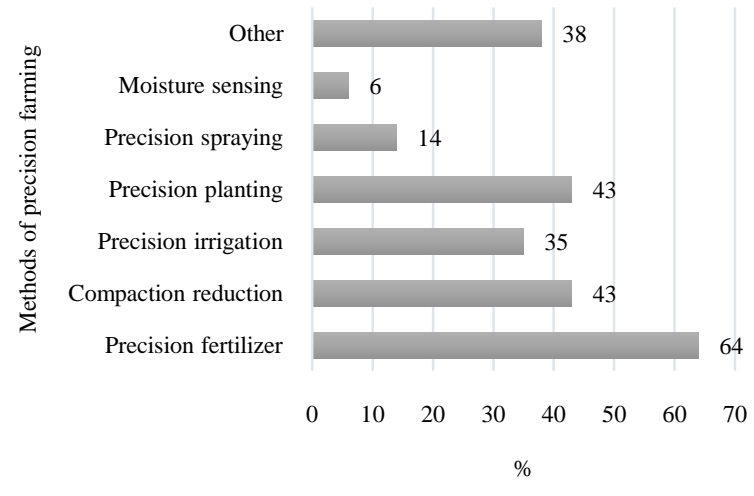

Fig. 2. Precision farming addressable market by technology, $\$$ bn

The next step is monitoring. This area is developing very interestingly. Projects such as the Israeli Taranis [4] already make it possible to recognize photographs and identify malicious objects that appear in the field. You can monitor the status of crops in different ways: small fields - visually, large - with the help of flying around with drones with further recognition of photos. This will allow timely implementation of preventive measures related to the competent protection of crops.

In principle, today every farmer should use gadgets. Already there are so many simple mobile applications with which you can do basic monitoring, scouting. Old models are a thing of the past.

Further development is the targeted pesticide application. Already there are options when first a map of the lesions is created, and then a smart sprayer makes the necessary substance only within the affected area.

Any large field can be heterogeneous in terms of nutrients. Therefore, if you do not take this into account, you will have to make one norm throughout the site. In this case, after harvesting, zones in the field will appear on the yield map in

There is the term of zone management when the field is divided into certain zones of productivity. And when forming the technology, individual norms for each zone can be taken into account. After approval, the data goes to the orders, to the task cards.

It is hoped that the next technological breakthrough will be the recognition and simultaneous pesticide application.

After harvesting we get the actual data. They can be compared with the planned ones. This will allow us to summarize: what happened and how accurately we worked with the norms in different zones. Not all fields are different, but there are many areas with different nutrition zones.

Large agricultural holding companies take into account such aspects, because it has influence on both optimization of costs and increased yield. Small farms are not yet. This is due to the fact that they need to contact the laboratory, need a technician with the appropriate equipment.

Suppose an enterprise has implemented certain basic technologies. There is already a system in which all fields, its contours, land plots are established. There is a history, laboratory data. This data is already correctly used in planning. There is a technique with precision farming equipment. Target application cards for spot application or which the yield will lag behind.

differentiated sowing have been introduced, and information on the performance of operations is collected.

But each of these blocks continues to evolve. In the foreseeable future, equipment without machine operators will be used. Algorithms for recognizing diseases or defining the level of nutrients in the leaf surface will be improved. The sensors in the field will improve, and batteries will appear which can serve for a long time. Specialized data transmission networks will be developed, for example LoRaWAN type [5], with which it can be collected information from fields and equipment in the area where GSM coverage is not available. Definitely, the development of big data processing algorithms will continue too.

The University of Nebraska-Lincoln [6] conducted research based on a survey of 126 agricultural producers in the United States which implemented precision farming technologies. As a result of the research, it was found that the most popular were high-speed Internet and agrochemical soil sampling. The following positions include yield monitoring, maps and GPS guidance system. The differential fertilizer application system is also gaining popularity, but the use of satellite and aerial imaginary is still new for digitalizing the agricultural sector, its implementation has so far accounted for about 30\%, but is gaining popularity (Fig. 3) [7].

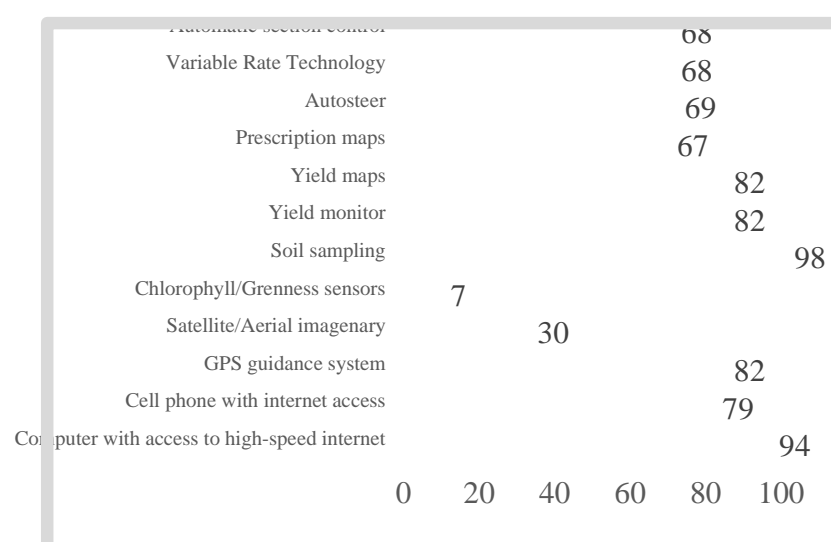

Fig. 3. Implementation of precision farming technology, $\%$.

If we take the aforementioned DigitalAgribusiness system as an example, then the more quality statistics it contains, the more information there will be for training the algorithms. And the better it will work.

Now DigitalAgribusiness describes all the rules, all technical lists for wheat, corn, sunflower, soy, rape - all the main crops. But in Ukraine, more crops are grown, so it can be added a library of technologies for these crops and improve the algorithm. The system allows to do this.

\section{DISCUSSION}

European Union, which is interested in the development of digital agriculture, has a model of work now that was built with the formation of centers of competence in the directions 
of: IoT, farm management, big data and so on.

Britain has Agri-EPI Center [8] and the government partnerships in the field of precision farming because they have a share in this structure, invests in the development of innovations, including in the agricultural sector. One of the interesting developments created as part of this project is a 3D map of the UK soils.

Ukraine has no electronic map of soils, and there it is created a 3D map, which allows, among other things, to make interesting correlations when applying different layers of data on the soil. This is a huge amount of work. And there the state takes a leading role in the implementation of such projects, because it understands the value of innovation in this area and public-private partnerships work in this country [10]. The working model is to come and see its R \& D centers.

Ukraine is are only beginning to realize the need for the state to encourage the development of the digitalization of agricultural business. In 2020, 680 million UAH will be invested in agricultural investment projects [11]. This is not much for the set goals, but for the start there is already something (Fig. 4).

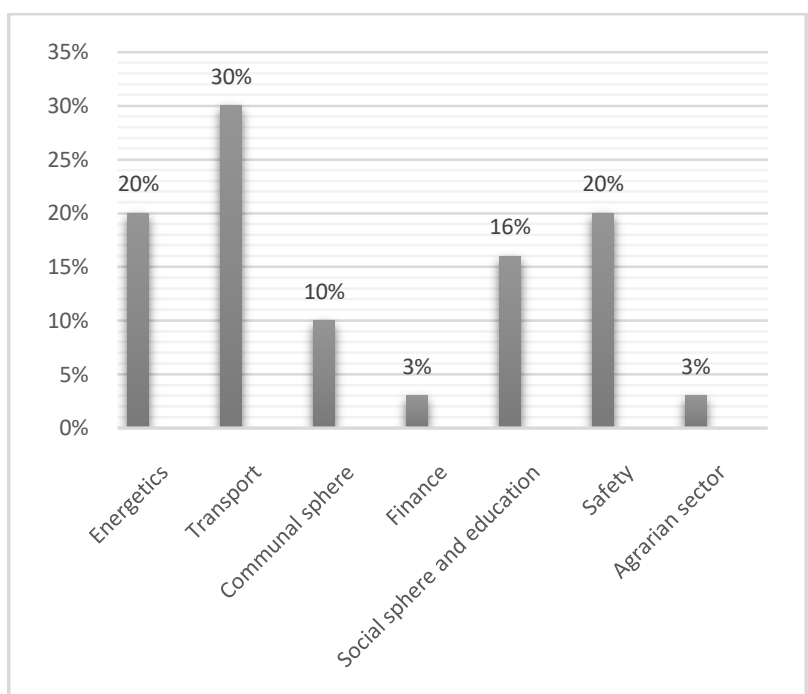

Fig. 4. Distribution of credit funds in the amount of UAH 22662 billion attracted for the implementation of investment projects

The optimality in digitalization is when leader trust his production plan, understand that it is based on high-quality data, and trust the algorithms that participated in the calculation of this plan, and we can realize this wonderful plan.

The point of optimality in digitalization is when in online mode it can be seen all the analytics from the fields during the implementation of work in the field and in the process of monitoring crop growth. Find out how the spring campaign is going, how the autumn campaign is, how many of the planned areas were cultivated, equipment development, costs, problems. That is, all valuable analytics for managing processes, for changes in processes and its improvement will be available on a smartphone or workpad [12].

The leader must see all his fields, he must see the profitability of each field, the dynamics of the development agency Innovate UK [9], which conduct private-public

of cultures. This will allow to analyze the results: how all the elements of this campaign worked.

The leader must understand that, as part of the phenophase, the agronomist went out clearly on certain days and carried out inspections, filled out acts, attached photos. Similarly, for other operations. And then by the end the planned results can be achieved.

\section{CONCLUSION}

Agricultural business is a type of activity that is based on a huge amount of data. Until recently, all this information was accumulated by an agronomist. He defined what would be good for his farm next year: what crop rotation to use; which hybrids to buy; what are the norms of fertilizers in order to get optimal productivity. In addition, to grow a good crop and optimally use land resources is a difficult task and requires constant monitoring, which cannot be carried out efficiently in large areas. High-tech solutions, including precision farming, helps to solve this task in modern agriculture. The experience of American farmers vividly demonstrates the profitability of introducing precision farming tools, despite of the sufficient land supply of the American continent. The future of the agricultural sector belongs to the technological innovations. When the process of "technology race" is already actively gaining momentum in the world, countries like Ukraine, in spite of vast field areas, should already be introduced into this process so as not to remain at the end of the chain of successful agricultural producers.

\section{REFERENCES}

1. Official website of informational agricultural portal LATIFUNDIST. Available at: <https://latifundist.com/novosti/38006-kernel-prezentova 1-innovatsionnoe-reshenie-dlya-upravleniya-biznesom>

2. Precision farming report of Goldman Sachs Company. Available $<$ https://docdrop.org/static/drop-pdf/GSR_agriculture-N1 sH6.pdf>

3. Official website of MapExpert Group. Available at: $<$ http://mapexpert.com.ua/index_ru.php?id=20\&table=ne ws>

4. Official website of Taranis Company. Available at: <http://www.taranis.ag/>

5. Official website of LoRaWan network architecture Available at: 〈https://lora-alliance.org/about-lorawan〉

6. Official website of Institute of Agriculture and Natural Resources of Nebraska extension. Available at: $<$ https://extension.unl.edu/>

7. Official website of Swiss-based environmental intelligence platform Gamaya. Available at: $<$ https://medium.com/remote-sensing-in-agriculture/digit al-technologies-in-agriculture-adoption-value-added-andoverview-d35a1564ff67>

8. Official website of the The Agricultural Engineering Precision Innovation Centre. Available at <https://www.agri-epicentre.com>

9. Official website of United Kingdom Research and Innovation. Available at <https://www.gov.uk/government/organisations/innovate -uk> 
10. Reznik, N.P., Demyan, Y.Y., Tokar, Y.I., Gupta, S.K., Ostapchuk, A.D. (2019): Mechanism of investment maintenance for the sustainable development of the agricultural sphere. International Journal of Engineering and Advanced Technology, 8 (11), pp. 112-116.

11. Official website of AgroPortal. Available at: <http://agroportal.ua/news/vlast/gosbyudzhet2020-v-agra rnye-investproekty-volyut-680-mln-grn/\#>

12. Smoliy, L., Revutska, A., Novak, I. (2018). Influence of innovation factor in economic dynamics in Europe. Marketing and Management of Innovations, 1, pp. 247-258. 